\title{
Do instituto da suppressio: em perspectivas tradicional e contemporânea
}

\author{
Miguel Augustin Kreling*
}

\section{INTRODUÇÃO}

A suppressio é um neologismo felizmente cunhado por Menezes Cordeiro com a finalidade de exprimir, de uma forma desprovida de preconceitos e em substituição da tradução usual por "caducidade", ${ }^{\prime}$ a idéia designada Verwirkung no Direito alemão. Ela consiste sumariamente na perda de um direito pelo seu nãoexercício prolongado, sob certas circunstâncias, exigida pela boa-fé objetiva. ${ }^{2}$

Ela tem origem jurisprudencial. Suas raízes mais profundas encontram-se em casos relativos a vendas de ofício, em benefício do comprador, julgados pelo então Reichs-Oberhandelsgericht ${ }^{3}$ (ROHGE). ${ }^{4}$
Uma primeira decisão clara de suppressio - do Rohge, de oito de abril de 1873 - não trata, contudo, de vendas de ofício. Trata do seguinte: o comprador, num contrato de fornecimento, reclama ao vendedor da má qualidade do produto recebido; este envia-lhe uma carta requerendo provas concretas dos defeitos alegados e, até o seu levantamento, decide suspender o fornecimento; o comprador cala-se e, passados dois anos, exige a execução do contrato nos termos acordados; perante tais fatos, o Rohge decide que essa conduta é completamente inconciliável com a boa-fé assim como é requerida no tráfico comercial. $^{5}$

\footnotetext{
* Acadêmico da Faculdade de Direito da UFRGS.

1 Cf. NORONHA, Fernando. O Direito dos Contratos e seus Princípios Fundamentais: autonomia privada, boa-fé, justiça contratual. São Paulo: Saraiva, 1994. p. 185.

2 Ibidem, p. 185.

3 Supremo Tribunal Comercial do Reich (tradução livre).

4 CORDEIRO, António Manuel da Rocha e Menezes. Da Boa-Fé no Direito Civil. Coimbra: Almedina, 1997. p. 798-810.

5 ALEMANHA. ROHGE: 8 abr. 1873, ROHGE 9 (1873), 406-413 (412) apud CORDEIRO, op. cit. p. 799.
} 
Quatro anos volvidos, acha-se uma segunda decisão judicial referente a esse tema, cujo relator arrisca-se a tecer ineditamente as suas linhas gerais:

O exercício de um direito contratual pode ser limitado no tempo, quando tal limite derive da consideração da boa-fé e da natureza das coisas, sempre que o exercício retardado desse direito contratual conduzir a uma desvantagem injustificada para a outra parte. ${ }^{6}$

O primeiro tratamento doutrinário à suppressio foi dado, na década de 1930 , por Endemann e Krause, os quais teoricamente lhe reconduziram não à boa-fé, mas sim ao Verschweigung - instituto germânico medieval que se pode traduzir por "silenciamento". Segundo esse instituto, aquele que, tendo um direito seu estorvado por outrem, calar-se "durante ano e dia", ${ }^{7}$ não poderá mais reclamá-lo; assim se verificava na usucapião. Uma vez que a jurisprudência manteve-se indiferente a tal construção negando à suppressio qualquer laço cultural e dogmático e justificando-a mediante recurso exclusivo à bona fides - ela é de interesse estritamente histórico. ${ }^{8}$

O caos econômico e a hiperinflação que marcaram o período entre a Primeira e a Segunda Guerra Mundial desempenharam um papel crucial à consagração da suppressio. Em tais condições, o exercício retardado de direitos contratuais poderia desencadear efeitos ruino- sos à contraparte. Além disso, a construção jurisprudencial do direito de valorização monetária, derivada da boa-fé como instrumento indispensável ao tráfico jurídico em contextos fortemente inflacionados, vinha sendo aplicada com excessos manifestamente injustos. Fazia-se necessário aos aplicadores do Direito "prescricionar" - também pela boafé, já que a legislação se omitia a esse respeito - o direito do credor de pedir, para compensar a depreciação monetária, o reajustamento do seu crédito, pois o seu exercício retardado poderia causar desvantagem intolerável ao devedor. Nesse contexto, especialmente na tentativa de modular a valorização monetária, constatou-se a importância social do que se pode designar "extinção de direito por exercício contrário à boa-fé"."

O Direito Comercial (como dos casos supramencionados), pela sua maior escassez de regras de prescrição e decadência, foi, diferentemente de outros ramos do Direito, campo fértil ao progresso da suppressio. Esta, acompanhando o alargar sofrido pela boa-fé, difundiu-se, embora já com mais dificuldades, também para outras áreas. Primeiramente o fez ao Direito da concorrência e do trabalho; mais tarde, alastrou-se pelo Direito privado e infiltrou-se até mesmo nos Direitos processual e público. Por fim, concentrou a sua atividade nas esferas de maior dinamismo econômi-

6 CORDEIRO, op. cit. p. 800 ALEMANHA. ROHGE: 20 out. 1877, ROHGE 23 (1878), 8387 ( 83 e 85$)$.

7 Ibid., loc. cit.

8 CORDEIRO. Da Boa-Fé...p. 800-801.

9 Ibid., p. 801-802. 
co: ${ }^{10}$ Direito da concorrência (marcas e patentes); setores de transição, v.g., Direito autoral; áreas jurídicas de elevada sensibilidade social, v.g., locação; setores de relacionamento difícil, v.g., relações emergentes da Segunda Guerra Mundial, do imediato segundo pósguerra e envolvendo nações do bloco soviético.

Apesar dessa grande difusão da Verwirkung, aquela não se deu sem críticas. Os negativistas acusavam-na de, em nome da justiça material, suscitar inseguranças insuportáveis. Eles, no entanto, não resistiram ao impulso jurisprudencial que acabou por consolidar a suppressio, de tal forma a evitar que se restringisse a zonas restritas do Direito. ${ }^{11}$

Houve também tentativas, posto que sem sucesso, no sentido de desfigurar essa figura jurídica. Alguns autores defendiam que, quando do não-exercício de direito contratual, defluiria de seu titular uma declaração volitiva de renúncia, cuja vinculatividade (do tipo negocial) impediria uma atuação posterior. ${ }^{12}$ Entretanto, a ausência de elementos tais como forma, consentimento e circunstâncias negociais - essenciais a qualquer manifestação de vontade socialmente vista como destinada à produção de efeitos jurídicos ${ }^{13}$ - tornava tal doutrina facilmente refutável.
A partir da década de 1970, porém, a suppressio passou a ser, quase que unanimemente, reconduzida, pela doutrina, na esteira da jurisprudência, ao princípio da boa-fé. Isso se conserva, cada vez mais consolidado, ainda hoje. ${ }^{14}$

Por outro lado, da boa-fé objetiva à sua recondução ao abuso de direito, a Verwirkung percorreu um longo caminho - por vezes, polêmico - mediado pela exceptio doli e venire contra factum proprium. ${ }^{15}$

É justamente esse último passo dado pela suppressio - que a faz identificarse com o abuso de direito - que, pela sua artificialidade, pretende-se, com esta pesquisa, investigar.

Um instituto de tal relevância à justiça substantiva - a suppressio - não pode permanecer sendo obscuramente reconduzido à categoria do abuso de direito, sem que para tanto se aduzam sólidos sustentáculos justificativos, sob pena de ser, de outra forma, o seu espírito desvirtuado. Desse modo, se se tivesse de estatuir uma pergunta inicial que motivara e impulsionara esta pesquisa, apesar do interesse pelo estudo da Verwirkung em si, ela seria: a suppressio pode enquadrar-se dentro da categoria do abuso de direito?

Em razão da necessidade de restringir-se o campo no qual se procederá essa pesquisa, a suppressio será inves-

10 CORDEIRO. Da Boa-Fé..., p. 802-805.

11 Ibid., p. 805-806.

12 Ibid., p. 807.

13 AZEVEDO, Antônio Junqueira de. Negócio Jurídico: existência, validade e eficácia. 3. ed. rev. São Paulo: Saraiva, 2000. p. 120.

14 CORDEIRO, op. cit., p. 807-809.

15 Ibid., p. 807-810. 
tigada apenas enquanto for aplicável ao Direito privado.

A metodologia empregada é a comparativa, a partir da técnica de pesquisa bibliográfica.

A partir da análise dos pressupostos tradicionais e dos aspectos ainda não tão consagrados deste instituto, pretende-se concluir pela correção ou inexatidão da classificação da suppressio como forma de abuso de direito. Caso a conclusão repudie tal enquadramento, objetiva-se determinar qual a relação que há entre a perda e o abuso.

Para tanto, divide-se esta exposição em duas partes, e cada uma destas; em três capítulos. Enquanto a primeira visa investigar a suppressio pela ótica sob a qual ela é tradicionalmente abordada na doutrina, a segunda pretende apreciar aspectos que apenas mais recente e minoritariamente lhe são atribuídos.

A primeira parte compõe-se de três capítulos. No primeiro, relaciona-se o fenômeno do influxo dos fatos sociais sobre as normas jurídicas com a objetividade dos indícios de que o direito não será mais exercido. Já no segundo, examina-se o modo pelo qual a passagem do tempo repercute na verificação da Verwirkung. Por fim, estuda-se o limite que o princípio da boa-fé impõe à liberdade do exercício de direitos pelo seu titular, resultando na sua extinção por protraimento desleal.

A segunda estrutura-se da mesma forma. Primeiramente se investiga a sup- pressio sob a perspectiva do pólo oposto - o do seu beneficiário - ao que tradicionalmente se elege como ponto de partida para o seu tratamento científico. Em seguida, aprecia-se a aplicabilidade do conceito de sistema móvel à justificação formal da perda do direito por protraimento desleal do seu exercício. Por último, avalia-se se a suppressio pode ser corretamente enquadrada dentro da categoria de abuso de direito e, caso se conclua que não possa, sugere-se a relação que ela mantém com este.

\section{A SUPPRESSIO SOB UMA PERSPECTIVA TRADICIONAL}

A suppressio - ou Verwirkung, em alemão - consiste na situação do direito que, por não ter sido exercido, sob dadas circunstâncias, durante um certo período de tempo, não possa mais sê-lo, pois, caso contrário, infringiria o princípio da boa-fé. ${ }^{16}$

Se se analisar a suppressio analogicamente à estrutura da norma jurídica, dir-se-á que ela, sumariamente, imputa a perda do direito - conseqüência jurídica - ao não-exercício deste direito condição jurídica. ${ }^{17}$ A conseqüência jurídica da suppressio, pela sua própria natureza, dispensa, neste estudo, investigações. Contudo, a condição jurídica, ou melhor, quando efetivamente se verifica um não-exercício diferido no tempo e merecedor de ser feito norma, é complexa e, por isso mesmo, carece de aprofundamentos.

16 CORDEIRO, Da Boa-Fé... p. 797.

17 KELSEN, Hans. Teoria Pura do Direito: introdução à problemática científica do direito. São Paulo: Revista dos Tribunais, 2001. p. 67. 
Da própria definição da suppressio, constata-se que, para que ela se verifique, põem-se-lhe três condições. ${ }^{18}$

A primeira - "por não ter sido exercido, sob dadas circunstâncias" - é de cunho fático. Tal fato - o não-exercício circunstanciado - embora meramente permitido, em um primeiro instante, em um segundo, torna-se obrigatório, penetrando na dimensão jurídica e sendo, portanto, por ela, tutelado. Trata-se de um fato que ascende à condição de norma, isto é, em termos genéricos, do influxo dos fatos sociais sobre as normas jurídicas.

A segunda - "durante um certo período de tempo" - é de caráter temporal. Atribui ao fato, para que este se possa investir de normatividade, um requisito - que se estenda por um dado lapso de tempo. Trata-se da repercussão do tempo nas relações jurídicas.

A terceira - "pois, caso contrário, infringiria o princípio da boa-fé" - é de natureza moral. Consiste na boa-fé objetiva. É esta que reveste a inação estendida no tempo de normatividade, a ponto de tornar o retorno ao exercício do direito um ato ilícito. Trata-se da influência do princípio da boa-fé sobre a liberdade de exercício de direitos subjetivos.
São essas as três condições da $s u$ ppressio. A fim de investigar a natureza desta, cumpre essencialmente inquirir a daquelas. Cada uma delas, como se evidenciou, relaciona-se a uma questão jurídica mais genérica. Daí o interesse de dedicar esta primeira parte ao exame dessas questões gerais bem como a maneira pela qual elas se aplicam e determinam a suppressio, sempre sob sua perspectiva tradicional.

\subsection{O Influxo dos fatos sociais sobre as normas jurídicas}

Este fenômeno do influxo é corolário do princípio da interdependência dos fenômenos do mundo social e jurídico, ínsito à própria essência social do Direito. ${ }^{19}$

É corrente na doutrina a exigência de que haja indícios objetivos de que não haverá mais atuações do direito em questão, para que a suppressio se constate. Assim, havendo neles uma dada configuração da efetividade social que se tem por sólida, esta pode, sob a intervenção positiva de outros fatores que lhe complementem, investir-se de caráter normativo e ascender à dimensão do Direito ${ }^{20}$ eis a essência da suppressio.

18 NORONHA, O Direito dos Contratos... p. 185.

19 Cf. MIRANDA, Francisco Cavalcanti Pontes de. Systema de Sciencia Positiva do Direito. Rio de Janeiro: Jacintho Ribeiro dos Santos, 1922. p. 18-19. ROUBIER, Paul. Théorie Générale du Droit: histoire des doctrines juridiques et philosophie des valeurs sociales. 2. ed. rev. e aum. Paris: Sirey, 1951. p. 74-82.

20 Adquire assim a proteção a que uma eventual intervenção coercitiva do poder público corresponde. Cf. RÁO, Vicente. O Direito e a Vida dos Direitos. São Paulo: Max Limonad, 1960. v. 1, p. 41. 
A Verwirkung, enquanto momento normativo, se analisada da perspectiva do tridimensionalismo jurídico, ${ }^{21}$ resulta da tensão entre fato - omissão do exercício - e valor - segurança jurídica, especificada na forma de confiança. Estes estão correlacionados por "implicaçãopolaridade". ${ }^{22}$ Neste caso peculiar, quando o não-exercício - fato - mereça ser conservado tendo em vista a confiança no tráfico negocial - valor - a esta conservação aspira a suppressio - norma. ${ }^{23}$

O influxo da efetividade social sobre o Direito, justificável mediante a suppressio, pode dar-se parcial ou completamente.

Se um credor de alimentos, por um longo período de tempo, não exerce a sua pretensão de recebê-los contra o alimentante, uma eventual ação de cobrança sob pena de prisão civil - art. $733^{24}$ do Código de Processo Civil (CPC) fica restrita às três últimas prestações, podendo a quantia restante ser reclamada tão-só por meio de artifício processual menos severo. Trata-se de um caso de execução por quantia certa. ${ }^{25}$ Aqui, já que o direito do alimentado sofreu restrições, mas não se extinguiu, diz-se ter havido suppressio parcial.

Em julgado da 5aa Câmara Cível do Tribunal de Alçada do Rio Grande do Sul, nota-se a ocorrência de suppressio completa. $O$ inquilino absteve-se de pagar aluguel por quatro anos. Em função disso, o locador, alegando inadimplência, entrou com uma ação de execução sob pena de despejo. Esse Tribunal, em virtude do irrazoavelmente longo lapso temporal transcorrido, não proveu tal ação, justificando essa decisão pela adesão abdicativa (como denomina a suppressio), que convertera o contrato locatício em outro, de comodato. ${ }^{26}$ Desse modo, o locador (agora vertido em comodante) perdeu totalmente o direito às prestações previamente inerentes ao contrato de locação que concluíra.

Ademais, a título de ilustração, observa-se que é sólida a posição jurisprudencial segundo a qual, em um compromisso de compra e venda de imóveis dotado de cláusula de arrependimento, esta não pode ser invocada caso já se tenha adim-

21 Consoante o qual, "o Direito é uma integração normativa de fatos segundo valores", interagentes conforme a dialética da complementaridade. REALE, Miguel. Teoria Tridimensional do Direito. 5. ed. rev. e aum. São Paulo: Saraiva, 1994. p. 91.

22 Ibid., p. 57.

23 Ibid., p. 57

24 Art. 733, CPC: "Na execução de sentença ou de decisão, que fixa os alimentos provisionais, o juiz mandará citar o devedor para, em 3 (três) dias, efetuar o pagamento, provar que o fez ou justificar a impossibilidade de efetuá-lo. § 1 .o Se o devedor não pagar, nem se escusar, o juiz decretar-lhe-á a prisão pelo prazo de 1 (um) a 3 (três) meses. $§ 2.0$ O cumprimento da pena não exime o devedor do pagamento das prestações vencidas e vincendas. § 3.o Paga a prestação alimentícia, o juiz suspenderá o cumprimento da ordem de prisão".

25 SANSEVERINO, Paulo de Tarso Vieira. Estrutura Clássica e Moderna da Obrigação. In: MEDEIROS, A. P. C. (Org.). Faculdade de Direito da PUCRS: o ensino jurídico no limiar do novo século. Porto Alegre: EDIPUCRS, 1997. p. 303.

26 Ibid., p. 303. 
plido o preço integral do negócio, mesmo antes de assinado o instrumento público. ${ }^{27}$ Assim, a aplicação da suppressio completa - que é a mais comum - priva o vendedor do direito protegido, a princípio, pelo art. $1.088^{28}$ do Código Civil Brasileiro de $1916(\mathrm{CC} / 1916){ }^{29}$

\subsection{A repercussão do tempo nas relações jurídicas}

Como o ser humano está imerso no tempo, e o Direito trata de relações humanas, é inevitável que este não seja indiferente à evasão do tempo ${ }^{30}$ ora requer simultaneidade - como no consentimento negocial - ora reage sobre a sua irreversibilidade - como na nulidade dos atos jurídicos ligada a termo e condição e na prescrição e decadência; ${ }^{31}$ a que se acresce, por proximidade conceptual, a suppressio.
Contudo, enquanto a ação prescritiva do Direito não se consuma, o tempo é reversível ao arbítrio do credor. Isso se deve à incursão da ética no dado normativo, a qual, à medida que se dissemina, força os prazos prescricionais a dilatarem-se. ${ }^{32}$ Eles justificam-se, portanto, só materialmente, onde atua a boa-fé na implementação da segurança jurídica ${ }^{33}$

Tais prazos, uma vez decorridos, provocam a regressão das partes, pela reversão do tempo sobre si mesmo diante de uma exigência ética, ${ }^{34}$ ao estado em que se encontravam anteriormente à aquisição do vínculo jurídico, como se este jamais houvesse se dado. ${ }^{35} \mathrm{Na}$ Verwirkung, raciocina-se similarmente, senão pelo que se restringe geralmente à situação de um direito, ou de um complexo destes.

O objetivo proeminente da suppressio $^{36}$ consiste em complementar as dis-

27 BRASIL. Supremo Tribunal Federal. Súmula n.o 166. É inadmissível o arrependimento no compromisso de compra e venda sujeito ao regime do DEL 58, de 10.12.1937. Disponível em: <http://www.stf.gov.br/jurisprudencia/jurisp.asp>. Acesso em: 14 abr. 2002.

28 Art. 1.088, CC/1916: "Quando o instrumento público for exigido como prova do contrato, qualquer das partes pode arrepender-se antes de o assinar, ressarcindo à outra as perdas e danos resultantes do arrependimento, sem prejuízo do estatuído nos arts. 1.095 a 1.097".

29 NORONHA. O Direito dos Contratos... p. 185-186.

30 O Direito revela, na verdade, a luta vitoriosa do espírito humano, na aspiração pela eternidade, contra o tempo. Cf. LIMA, Ruy Cirne. Preparação à Dogmática Jurídica. 2. ed. Porto Alegre: Sulina, 1958. p. 231.

31 Ibid., p. 220 e 227.

$32 \mathrm{Na}$ Lei das Doze Tábuas, a aquisição de propriedade por usucapião exigia a posse por um ano, quanto a coisas móveis, e dois, quanto a imóveis. Cf. ALVES, José Carlos Moreira. Direito Romano. 4. ed. rev. e acrescentada. Rio de Janeiro: Forense, 1979. v. 1, p. 424. Atualmente, v.g., no Direito pátrio, os prazos são respectivamente, em termos genéricos, três e dez anos. Cf. arts. 1.260 e 1.242, do Código Civil Brasileiro de 2002 (CC/2002).

33 LIMA. Preparação... p. 228-229.

34 Ibid., p. 331.

35 Ibid., p. 229-220. Art. 182, CC/2002.

36 CORDEIRO. Da Boa-Fé... p. 816. 
posições legais - onde estas, consoante a boa-fé objetiva, forem inexistentes ou insuficientes - acerca da influência do tempo nas relações jurídicas. Assim, quanto mais "prescricionado" for um ordenamento qualquer, menor será o espaço a ser preenchido pela Verwirkung. Disso provém a sua natureza subsidiária. ${ }^{37}$

Além de completar, incumbe à suppressio eticizar um direito formalista da decadência, concedendo-lhe maleabilidade, o que tem por contrapartida a atribuição aos juízes de uma discricionariedade não imune ao desvirtuamento do direito legislado. ${ }^{38}$

A Verwirkung busca orientar a realidade em que o não-exercente, pela sua inação reiterada no tempo, gera, no espaço jurídico, uma imagem de não-atuação. Esta cria, naqueles a quem tal direito afetaria caso fosse exercido, uma certa expectativa, a qual, desde que fundada objetivamente, deve, em decorrência do princípio da boa-fé, ser juridicamente tutelada. A tutela jurídica da expectativa social gerada pela inação é o que se traduz por suppressio, já que implica interdição do exercício superveniente. Assim, a Verwirkung, como a proi- bição do venire contra factum proprium, almeja banir condutas contraditórias.

Nada obstante, o que então as diferencia? Cordeiro preconiza que é justamente a relevância do fator tempo que o faz: para que se justifique a perda de um direito pela suppressio, a exigência do decurso do tempo é, em razão da maior severidade de seus efeitos, sensivelmente de maior relevo, do que se o fizesse mediante venire contra factum proprium. ${ }^{39}$

O lapso temporal demandado, entretanto, é variável, porque está subjugado ao princípio da boa-fé: aquele se estende até o instante em que a representação gerada pela inatividade que se projeta na ambiência social justifique ser amparada por este.

Assim, analogamente à decadência, é a ação do tempo sobre a inércia (desleal) de seu titular que conduz à perda do direito.$^{40}$ Contudo, o critério decisivo da Verwirkung, não é o mero decurso do tempo associado à inatividade do titular, mas - e é isso que a diferencia da prescrição e decadência - a situação de justificada confiança que cria no oponente de que o direito jamais seria exercido. ${ }^{41}$

37 CORDEIRO. Da Boa-Fé., p. 812.

38 WIEACKER, Franz. História do Direito Privado Moderno. 2. ed. Lisboa: Calouste, 1993. p. 596-597.

39 CORDEIRO, op. cit., p. 813.

40 SANSEVERINO. Estrutura Clássica... p. 302.

41 LARENZ, Karl. Derecho Civil: parte general. Madrid: Revista de Derecho Privado, 1978. p. 302 . 
Vincula-se a suppressio à decadência,${ }^{42}$ ora pela imprecisão terminológi$\mathrm{Ca},{ }^{43}$ ora pela sua equivalência de efeitos e fim. Quanto aos efeitos, ambas concorrem para a extinção de direitos, ${ }^{44}$ visando, quanto ao fim, à promoção da segurança e da paz públicas e, subsidiariamente, ao desestímulo à negligência do titu$\operatorname{lar}^{45}$ - dormientibus non succurrit jus. ${ }^{46}$

Além disso, ambas inseriram-se no Direito por via jurisprudencial, excepcionando a antiga regra da perpetuidade dos direitos. A Verwirkung, tendo surgido na jurisprudência alemã,${ }^{47}$ pelo menos na ordem jurídica pátria, ainda opera só como recurso justificativo de soluções judiciais. A decadência (como a prescri- ção, supõe-se), pelo contrário, apesar de advir do Direito pretoriano, ${ }^{48}$ ganhou, há muito tempo, resguardo na legislação. ${ }^{49}$

Diferenciam-se elas, em contrapartida, tanto pelo meio mediante o qual atingem seu objetivo quanto pela classe de direitos que lhe são alvos, bem como pela exigência que buscam satisfazer. Em relação ao meio, a primeira efetiva-se ao surgir da confiança legítima na permanência de uma situação fática - pela intervenção da boa-fé objetiva - decorrido, até então, certo lapso temporal; a segunda, desconsiderando a situação fática específica, presume que já há confiança (mesmo que indeterminada) digna de tutela, deflui-

42 Alguns autores, v.g., Fernando Noronha (NORONHA. O Direito dos Contratos... p. 186), vinculam, por analogia, a suppressio também à prescrição. Esta posição, contudo, não se adota neste estudo. Aqui, divergentemente, se adere à posição segundo a qual a prescrição refere-se à extinção de ação condenatória - subsistindo, contudo, o direito cuja lesão lhe originou - e a decadência, a de direito (e só por via indireta, à extinção de ação constitutiva). Cf. AMORIM FILHO, Agnelo. Critério Científico para distinguir a prescrição da Decadência e para identificar as Ações Imprescritíveis. Revista dos Tribunais, São Paulo, v. 86, n. 744 , p. 725-750, out. 1997. p. 735 e 750 . Apesar de a distinção ser difícil na prática, desta última opinião compartilham Clóvis Beviláqua, Eduardo Espínola, Carpenter, Câmara Leal, Carvalho Santos, entre outros. Cf. GOMES, Orlando. Introdução ao Direito Civil. 18. ed. Rio de Janeiro: Forense, 2001. p. 505.

43 Não raramente, traduz-se do alemão (onde surgiu o instituto), Verwirkung por "decadência". Cf. LARENZ, Karl. Metodologia da Ciência do Direito. Tradução de José Lamego. 3. ed. Lisboa: Calouste, 1997. p. 600. A imprecisão terminológica existe pois "decadência" normalmente traduz a idéia de Befristung. Cf. MIRANDA, Francisco Cavalcanti Pontes de. Fontes e Evolução do Direito Civil Brasileiro. 2. ed. Rio de Janeiro: Forense, 1981. p. 163.

44 Cf. AMORIM FILHO, op. cit. p. 736; CORDEIRO. Da Boa-Fé... p. 798; LEAL, Antônio Luís da Câmara. Da Prescrição e da Decadência: teoria geral do direito civil. 2. ed. Rio de Janeiro: Forense, 1959. p. 115.

45 AMORIM FILHO, op. cit. p. 734 e 737.

46 Tradução: "O direito não aproveita aos que dormem [...]”. DORMIENTIBUS NON SUCCURRIT JUS. In: DINIZ, Maria Helena. Dicionário Jurídico. São Paulo: Saraiva, 1998. v. 2, p. 243.

47 CORDEIRO, op. cit., p. 798-799.

48 AMORIM FILHO, op. cit. p. 734.

49 Cf., v.g., arts. 207-211, CC/2002 e arts. 2.964-2.969, do Código Civil italiano. 
do, erga omnes e insuscetível de suspensão e interrupção, ${ }^{50}$ um período de tempo previamente (pela lei, ou pelas partes) estabelecido - tendo nada a ver com a boa-fé. ${ }^{51}$ Quanto aos direitos, àquela se sujeitam todos eles; ${ }^{52}$ a esta, só alguns dos potestativos. ${ }^{53}$ Por fim, a suppressio busca satisfazer a exigência de ajustar a situação de direito à de fato cuja duração no tempo justifique, a decadência, a de limitar temporalmente o exercício de um direito no interesse de outrem ou da comunidade..$^{54}$

De mais a mais, a primeira, pois existe só como artifício jurisprudencial, carece de pronunciamento judicial $e x$ officio ${ }^{55}$ para que ocorra. Já a segunda, em virtude de possuir regime legal ex- plícito, ${ }^{56}$ dá-se por si, sendo, por isso, independente de declaração ex officio. ${ }^{57}$

\subsection{A influência do Princípio da Boa-fé sobre a liberdade de exercício de direitos subjetivos}

Sumariamente parece um contra-senso punir o titular de um direito por protrair-se do seu exercício, ${ }^{58}$ como se lhe impusesse uma obrigação. Parece-o por infringir o próprio conceito de direito, visto que seu exercício abarca a possibilidade $^{59}$ do não-exercício; ${ }^{60}$ afinal neminem laedit qui suo jure utitur. ${ }^{61}$

Também o parece por transgredir dois princípios do exercício dos direitos: o da disponibilidade e o da inesgo-

50 Excepcionalmente se admite suspensão; v.g., contestação de paternidade (GOMES, op. cit., p. 508).

51 CORDEIRO, op. cit., p. 797. NORONHA. O Direito dos Contratos... p. 186.

52 Ibid. p. $810-812$.

$53 \mathrm{Ou}$ seja, apenas aqueles cujo não-exercício contribui mais intensamente à perturbação da tranquiilidade social, estando submetidos, por isso, a prazos especiais previstos em lei; v.g., direito à rescisão contratual bem como à propositura da ação respectiva, à contestação de paternidade, à anulação de casamento, direito de preempção (AMORIM FILHO, op. cit., p. 737-738).

54 Cf. GOMES, op. cit., p. 506.

55 Tradução: "Em razão do ofício [...]" (EX OFFICIO. In: DINIZ, op. cit. v. 2, p. 474).

56 Podendo, independentemente deste, ser ainda fixado judicial e convencionalmente (GOMES, op. cit. p. 508).

57 Cf. GOMES, op. cit. p. 508.

58 Pois, não despreza tal punição o valor econômico dos direitos positivos? Ora, esses só são adquiridos por meio de sacrifícios e esforços laboriais ou por transmissão de alguém que os fez. Além do mais, ela não desrespeita o sentimento de uma irresponsabilidade no exercício do direito subjetivo? Cf. RIPERT, Georges. A Regra Moral nas Obrigações Civis. São Paulo: Saraiva, 1937. p. 168.

59 REALE, Miguel. Lições Preliminares de Direito. 25. ed. São Paulo: Saraiva, 2000. p. 261. 60 MIRANDA, Francisco Cavalcanti Pontes de. Tratado de Direito Privado. 3. ed. Rio de Janeiro: Borsoi, 1971. v. 6. p. 71-72.

61 Tradução: "Não prejudica outrem aquele que usa de seu direito" (NEMINEM LAEDIT QUI SUO JURE UTITUR. In: DINIZ, op. cit., v. 3, p. 350). Cf. RIPERT, op. cit., p.134. 
tabilidade. Pelo primeiro, porque o direito (subjetivo) consiste em uma faculdade, ninguém pode ser obrigado a exercê-lo. Pelo segundo, os direitos, em geral, não se esgotam pela falta de exercício. ${ }^{62}$ Ambos compõem o princípio da liberdade de exercício. ${ }^{63}$

$\mathrm{Se}$ a isso se designar "absolutismo do direito individual", ${ }^{64}$ rebater-se-á que neste nada há de condenável, pois expressa juridicamente o desejo legítimo de atribuir e proteger a liberdade. ${ }^{65}$ Nesse sentido:

Não pode [...] escamotear-se uma intenção normativa prima de manter, uma vez concedido, o direito subjetivo: a permissão jurídica que o consubstancia, porque permissão, não implica exercício necessário e, porque jurídica, não tolera interferências exteriores que, do permitido, façam proibido ${ }^{66}$
Tal contrasenso procede, se desconsiderado for o princípio da boa-fé67 regra moral penetrando no dado jurídico e protestando contra seu rigorismo racionalista ${ }^{68}$ summum jus, summa injuria.$^{69}$ Daí resulta um terceiro princípio do exercício: o da normalidade. Assim não se admite o exercício anômalo, isto é, dissociado de sua função social $^{70}$ - exige-se o relativista. ${ }^{71}$ Esta idéia, até certa extensão, restringe a disponibilidade e a inesgotabilidade. A ela também se conecta o dever de exercício que acompanha certos direitos. ${ }^{72}$

Ao princípio da boa-fé, vêm-se reconduzindo, com sucesso, inúmeros institutos jurídicos, ${ }^{73}$ os quais, em razão disso, adquirem maior estabilidade e congruência conceituais e flexibilidade e amplitude operativas; deram assim

62 GOMES, op. cit., p. 130.

63 Cf. MIRANDA, op. cit. v. 6. p. 81.

64 Quer dizer: ilimitação do exercício e irrelevância de seu fim, desde que dentro dos limites do direito, típico de sistemas onde se admitem contradições na coexistência de direitos (Cf. MIRANDA, op. cit. v. 6, p. 89-90 e 92).

65 RIPERT, op. cit., p. 189.

66 CORDEIRO. Da Boa-Fé... p. 817.

67 Trata-se da boa-fé objetiva, que, opondo-se à boa-fé subjetiva, é um standard, um parâmetro objetivo e genérico, fundado na conduta normal que se pode razoavelmente esperar de um homem médio, de um bom pai de família. Cf. MARQUES, Cláudia Lima. Contratos no Código de Defesa do Consumidor: o novo regime das relações contratuais. 3. ed. São Paulo: Revista dos Tribunais, 1992. p. 106.

68 Cf. RIPERT, op. cit., p.134. RÁO. O Direito à Vida..., p. 70.

69 Tradução: "A justiça excessiva torna-se injustiça” (SUMMUM JUS, SUMMA INJURIA. In: DINIZ. Dicionário... v. 4. p. 463).

70 GOMES. Introdução... p. 130.

71 Quer dizer: limitado na coexistência com outros direitos, em virtude do princípio da nãocontradição, típico dos sistemas jurídicos modernos. Cf. MIRANDA, op. cit. v.6. p. 89-90.

72 Cf. Ibid., v. 6, p. 81-82.

73 V.g., responsabilidade pré-contratual, deveres de proteção, dever de assistência nas relações trabalhistas, dever de fidelidade do sócio, queda da base do negócio jurídico, abuso de direito (LARENZ, Karl. Metodologia da Ciência do Direito. 3.ed. Lisboa: Calouste, 1997. p. 600). 
um passo sólido em direção à intregralização da justiça material. Relativamente à suppressio, não se deu de forma diversa. ${ }^{74}$

O princípio da boa-fé, acometido de função socializadora, embora intransponível em proposição verbal, ${ }^{75}$ concretiza-se na norma segundo a qual é inadmissível qualquer comportamento que viole o mandamento de portar-se com lealdade e correção. ${ }^{76}$ No caso específico da suppressio, esse princípio, posto que uma de suas faces preconiza o hábito fiel e coerente de satisfazer as expectativas razoáveis alheias, respeitando e tendo consideração pela outra parte, ${ }^{77}$ vem revestido da teoria dos atos próprios. Conforme esta teoria, é ilícito lançar mão de um direito de modo a contrariar o sentido que razoavelmente se poderia inferir da conduta precedente de seu titular interpretada objetivamente com base na lei, nos bons costumes e na boa-fé (objetiva), ou quando o posterior exercício (atrasado) ofende disposição legal, os bons costumes e a boa-fé. ${ }^{78}$ Em suma, o não-exercício (mesmo de um direito que não implique dever de exercício) pode produzir conseqüências (extintivas), contrárias aos interes- ses de seu titular. ${ }^{79}$ Dessa forma, a boa-fé objetiva delimita (arcere) o conteúdo (ex) do direito, o qual é ação dentro (e jamais fora) de cerca ${ }^{80}$ Esta traça limitações que independem de ato jurídico e refletem-se no exercício do direito. ${ }^{81}$

É incorreto, todavia, interpretá-la como se proibisse absolutamente toda e qualquer contraditoriedade no comportamento humano. Isso equivaleria a desprezar a própria essência - volúvel, vulnerável, hesitante - do ser humano na Terra; enrijeceria a linearidade da evolução dos fatos sociais, extraindolhe a interessante imprevisibilidade da vida. A teoria dos atos próprios visa apenas abater certo nível de contradições comportamentais, modulando-o a ponto de preservar a relação de confiança recíproca minimamente necessária ao desenvolvimento regular do tráfico negocial; ${ }^{82}$ ou melhor, ela interessa-se pela não-contradição tão-só na proporção em que esta promova lealdade e confiança.

Essa teoria abarca duas figuras semelhantes - venire cotra factum proprium e suppressio. Estas, entretanto, distinguem-se. Além das diferenças referentes à estrutura (tempo demanda-

74 CORDEIRO. Da Boa-Fé..., p. 807-809. Cf. LARENZ, op. cit. p. 600.

75 LARENZ, op. cit. p. 410.

76 MARTINS-COSTA, Judith. A Boa-Fé no Direito Privado: sistema e tópica no processo obrigacional. São Paulo: Revista dos Tribunais, 1999. p. 457.

77 MARQUES, Contratos... p. 106-107.

78 MARTINS-COSTA, op. cit. p. 460.

79 MIRANDA. Tratado de... v. 6. p. 82.

80 Cf. Ibid., v. 6, p. 80.

81 Cf. Ibid., v. 6, p. 89.

82 MARTINS-COSTA, op. cit., p. 470. 
do) e aos efeitos (severidade), aplicamse em níveis distintos de generalidade. Embora ambas objetivem a promoção da lealdade, confiança e segurança no tráfico jurídico, a primeira preocupase em controlar a "contradizibilidade" de condutas (constituam elas ação ou omissão) em geral, ${ }^{83}$ enquanto a segun$\mathrm{da}$, em especial, em suprimir exercícios de direito intoleráveis, em face de seu estado de inatividade anterior (isto é, necessariamente omissão).

Meras tolerâncias do credor, quer por complacência e consideração em relação ao devedor, quer por sua própria comodidade, não constituem obviamente um protraimento desleal, pois são inaptos a gerar qualquer expectativa legítima em um bonus pater familias ${ }^{84}$ no sentido de sua solidez; o devedor tem de contar normalmente com o exercício do direito de crédito. ${ }^{85}$ Todavia, à medida que tal condescendência desnatura-se em regularidade pela inatividade persistente do titular, já que non enim negligentibus subvenitur, ${ }^{86}$ ela torna-se manifestamente excessiva; dessa maneira, um casual retorno ao exercício do direito seria, consoante o princípio da boa-fé, de objetiva deslealdade e intolerabilidade.$^{87}$ Desse modo, a Verwirkung consiste na decadência do direito exercido imoralmente. ${ }^{88}$

Em virtude da boa-fé objetiva, combate-se a subjetividade na determinação da suppressio. Daí decorre que não se faz necessária qualquer culpa (e também consciência ${ }^{89}$ ) por parte do titular não-exercente (embora a má-fé, é claro, acresça justificabilidade à operatividade da Verwirkung $).{ }^{90}$ Em princípio, assim como na decadência ${ }^{91}$ (porém, nesta, não em razão da boa-fé), basta a não-atuação do direito objetivamente considerada. ${ }^{92}$

\section{A SUPPRESSIO SOB UMA NOVA PERSPECTIVA}

Nesta segunda parte, em justaposição, ou, por vezes, em contraposição, ao que foi desenvolvido anteriormente, pretende-se tratar três dos novos atributos contemporaneamente consignados à suppressio, por serem apenas estes os defensáveis e os dignos a serem

83 Ibid., p. 471.

$84 \mathrm{O}$ bonus pater familias é um conceito que juridicamente se tem como um ponto de referência na avaliação do grau de diligência que exige na conduta de um indivíduo (BONUS PATER FAMILIAS. In: DINIZ, op. cit., v. 1, p. 432).

85 LARENZ. Derecho... p. 303.

86 Tradução: "Não se socorrem os negligentes". NON ENIM NEGLIGENTIBUS SUBVENITUR. In: CARLETTI, Amilcare. Dicionário de Latim Forense. 8. ed. totalmente rev. e ampl. São Paulo: Universitária de Direito, 2000. p. 431.

87 NORONHA. O Direito dos Contratos... p. 185-186.

88 RIPERT. A Regra Moral... p.164.

89 Cf. MIRANDA. Tratado... v. 6. p. 80.

90 NORONHA, op. cit. p. 187.

91 GOMES. Introdução... p. 506.

92 CORDEIRO. Da Boa-Fé... p. 812. 
incorporados à doutrina tradicional da Verwirkung. Se eventualmente forem inconciliáveis com os já incluídos, merecem então, sem dúvida alguma, preferência.

Primeiramente se sugere a inversão do ponto de partida do tratamento doutrinário da perda por protraimento. Em segundo lugar, preconiza-se a conveniência de aplicá-la, em nome da congruência lógica e flexibilidade operativa, segundo as regras do sistema móvel. Finalmente se conclui pela inexatidão da identificação da suppressio como forma de abuso de direito.

\subsection{A Surrectio proposta por Menezes Cordeiro}

O termo surrectio, proposto por Menezes Cordeiro, pretende traduzir a idéia constante no vocábulo alemão Erwirkung, cunhado por Canaris, em $1971 .^{93}$ Trata-se do mesmo instituto - a suppressio ou Verwirkung - mas com a sua formulação teorética repensada, já que vista sob um prisma diferente.

A razão pela qual se tornou conveniente inverter a perspectiva de abordagem desse instituto - o que, do ponto de vista doutrinário, é plenamente razoável e recomendável - consiste na sua recondução, relativamente recente, ao princípio da boa-fé. Efetivamente, hoje em dia, a boa-fé objetiva é a "pedra de toque" do funcionamento da suppres- sio, uma vez que ela determina se a mera não-atuação merece tutela jurídica e, caso mereça, por quanto tempo então o não-exercício deve estender-se para que haja perda do direito e quando exatamente a efetividade social (da omissão) adquire normatividade.

Como o princípio da boa-fé visa à promoção da lealdade e segurança no tráfico jurídico, ele tutela toda confiança $^{94}$ - razoavelmente justificável e fundada em elementos objetivos - que uma dada atuação gere na contraparte in concreto (no caso de uma relação jurídica obrigacional) ou em um bonus pater familias. Daí decorre que é exatamente no instante a partir do qual a outra parte passa a confiar legitimamente na representação de não-exercício do direito que lhe afeta que a boa-fé objetiva desencadeia a suppressio na esfera jurídica da parte contrária. Sendo assim, a causa eficiente ${ }^{95}$ da Verwirkung dá-se no âmbito da parte oposta àquela na qual se sentem os seus efeitos. ${ }^{96}$

Contudo, se uma parte perde um direito, v.g., o de cobrar o adimplemento de uma prestação - suppressio - a contraparte, sobre a qual anteriormente impendia o dever correspectivo, neste instante, adquire o direito que lhe corresponde, v.g., o de não ser compelida a tal adimplemento - surrectio. $\mathrm{Ou}$ melhor, o efeito - suppressio - supõe um contra-efeito - surrectio. Constatase assim que a Verwirkung faz-se sentir

93 CORDEIRO. Da Boa-Fé... 817.

94 NORONHA. O Direito dos Contratos... p. 187.

95 Causa efficiens ou causa-fato jurídico. Cf. AZEVEDO. Negócio... p. 151.

96 CORDEIRO. Da Boa-Fé..., p. 820. 
na esfera jurídica de ambas as partes pólos da relação jurídico-privada.

Se essa constatação procede, então se verifica uma incongruência lógica na doutrina tradicional: por que designar e explicar este fenômeno do ponto de vista da parte in suppressio -- onde tão-só emergem efeitos - quando o fato que lhe determina ocorre junto à parte in surrectio - onde, além de efeitos, dá-se a causa?

Do ponto de vista científico - que é o que dirige a presente análise - não se justifica persistir na perspectiva menos funcional. Por isso, prefere-se a da surrectio. ${ }^{97}$

Como se trata do mesmo fenômeno, visto sob a ótica oposta, ${ }^{98}$ as condições postas à sua verificação permanecem. Altera-se, no entanto, a sua proposição teórica.

Assim, a Erwirkung, passo a passo, transcorre consoante a seqüência seguinte: a) a situação jurídica de nãoexercício de um direito subjetivo projeta-se na efetividade social; b) esta, mediante indícios objetivos correspondentes, gera uma previsão de perpetuar-se constantemente na qual o beneficiário confia legitimamente; c) imputa-se ao prejudicado, a título de culpa ou dolo, a responsabilidade pela nor- matividade que está prestes a revestir o fato; d) o beneficiário, de boa-fé (subjetiva), crê, ou a tem pelo menos por provável, na regularidade da situação fática subjacente, acata os deveres de informação que no caso ocorrerem e não tem consciência de prejudicar a outrem; e) inexistem outras soluções impostas legalmente, v.g., prescricionais e decadenciais; f) o princípio da boa-fé, em nome da segurança jurídica, é chamado a tutelar a confiança do beneficiário; g) a boa-fé objetiva faz surgir um direito que, embora não existisse antes, juridicamente, na efetividade social era tido como se estivesse presente; h) assim que o Direito passe a corresponder a tais fatos, consuma-se a surrectio. ${ }^{99}$

Todavia, está ainda por esclarecer-se: como se justifica a extinção de um direito - Verwirkung - pelo surgimento de outro-Erwirkung? A constituição legítima de uma situação jurídica ativa acarreta, por incompatibilidade ${ }^{1(x)}$ - corolário do princípio da não-contradição do sistema ${ }^{101}$ - a extinção da situação jurídica passiva prévia (v.g., usucapião e acessão ${ }^{102}$ ). Sob este prisma, a suppressio é uma mera conseqüência da surrectio. ${ }^{103}$

97 Por razões de clareza e coerência terminológica, procura-se, nesta pesquisa, empregar exclusivamente a vocábulo suppressio - à exceção do primeiro capítulo da segunda parte pelo qual tal fenômeno ainda é majoritariamente designado na jurisprudência e doutrina, não obstante a sua inconveniência lógico-funcional e a preferência do autor.

98 SANSEVERINO. Estrutura Clássica... p. 302.

99 CORDEIRO, op. cit., p. 822.

100 Sobre extinção de direitos por impossibilidade de coexistência, usucapião e acessão, veja Pontes de Miranda (MIRANDA. Tratado... v. 11. p. 117 e 155).

101 Cf. MIRANDA. Tratado... v. 6. p. 89.

102 CORDEIRO. Da Boa-Fé... p. 815.

103 Ibidem, p. 823. 
Distinguem-se ademais dois tipos de surrectio. ${ }^{104}$ Quando se desvincula de uma adstrição, pela aquisição de uma permissão genérica de atuação, tem-se a surrectio ampla. Por outro lado, se se adquire uma vantagem particular, isto é, uma permissão de aproveitamento específica, verifica-se a surrectio estrita ou propriamente dita.

\subsection{0 conceito de sistema móvel aplicado à suppressio}

Diferentemente da rigidez com que a doutrina tradicional põe à suppressio três condições que se devem cumular para que ela se verifique, contemporaneamente, em favor de dar ao instituto maior flexibilidade aplicativa e coerência justificativa, compreende-as como elementos de um sistema móvel. ${ }^{105}$ Dessa forma, embora eventualmente falte uma delas, a Verwirkung ainda sucede, pela intensidade especial que as restantes podem, no caso concreto, assumir. ${ }^{106}$

Nesse sistema, a primeira condição - fática - é, contudo, necessária; não há suppressio sem não-exercício. Todavia, a intensidade com que se efetua é variável; dependendo de quão perceptíveis e persuasivos sejam os indícios objetivos de que a inação se consolide, esta condição pode suprir a ausência casual de uma das duas restantes.
Estas - temporal e moral - são móveis e, bem por isso, carecem de autonomia. Se hipoteticamente o tempo decorrido sem atuação for excepcionalmente extenso, na proporção inversa da intensidade da objetividade do nãoexercício, mesmo que a boa-fé objetiva não tenha confiança alguma a proteger in concreto - mas a proteção da segurança comunitária a justifique (assim como o faz à decadência) - a perda do direito por protraimento desleal de seu exercício pode ocorrer. Inversamente se a não-atuação superveniente for tão evidente a ponto de justificar a geração de confiança legítima, o princípio da boafé pode eventualmente produzir o devido efeito mesmo que o tempo transcorrido seja desproporcional e, sob a ótica tradicional, irrazoável.

Embora as três condições estejam, sob a sistemática móvel, elasticamente concatenadas, ${ }^{107}$ é imperativo que, no mínimo, duas delas realizem-se - a necessária e uma das móveis - e que o façam, compensando-se flexivelmente, na dependência da hipótese traçada, em uma intensidade superior à habitual.

\subsection{A suppressio enquanto prevenção do abuso de Direito}

Conforme o art. $187^{108}$ do Código Civil Brasileiro de 2002 (CC/2002), há

104 CORDEIRO. Da Boa-Fé..., p. 821.

105 Ibidem, p. 822.

106 Ibidem, p. 750.

107 Ibidem, p. 750.

108 Art. 187, CC/2002: "Também comete ato ilícito o titular de um direito que, ao exercê-lo, excede manifestamente os limites impostos pelo seu fim econômico ou social, pela boa-fé ou pelos bons costumes". 
abuso de direito quando o titular de um direito, "ao exercê-lo, excede manifestamente os limites impostos pelo seu fim econômico ou social, pela boa-fé ou pelos bons costumes". Assim, por pressupostos lógicos do abuso de direito, têm-se a existência e titularidade deste direito (que é então exercido sem a observância de certos limites).

Por outro lado, desde que, pelo princípio da boa-fé, se passe a tutelar juridicamente a expectativa social de continuidade do não-exercício, a suppressio provoca a extinção do direito, o qual, por isso mesmo, deixa de existir. Se o direito não existe, este não pode logicamente ser exercido (abusivamente). Qualquer tentativa, no entanto, de voltar a exercê-lo consistiria em um ato não amparado por direito subjetivo algum e, assim, seria um ato ilícito propriamente dito (e não meramente abusivo), visto que causaria dano ao que confiou, de boa-fé, na sua inação.

Seguem, do exposto, duas proposições.

Primeiramente, se ainda se insistir que o titular que intentasse exercer um direito suprimido por suppressio dele abusaria, coloca-se que os instantes em que ocorre a Verwirkung e em que se dá o exercício abusivo são distintos. Veja-se bem. O não-exercício estendido no tempo de um direito não é abusivo nem, muito menos, ilícito, pelo próprio caráter de facultatividade que implica o conceito de direito subjetivo. Entretanto, essa não-atuação gera a expectativa social de sua perpetuação; se esta for objetivamente justificável, será digna de ser tutelada juridicamente. A tutela jurídica efetiva-se por ação da suppressio. Esta, embora, consoante este raciocínio - provisório - não extinga tal direito, limita-lhe completamente o exercício. Até o presente momento, como se vê, houve não-atuação desleal e, por isso, suppressio, porém não abuso de direito. Se, todavia, o suposto titular viesse supervenientemente perpetrar qualquer ação no sentido de reclamar tal direito de exercício limitado pela boa-fé, apenas então incidiria em abuso de direito. Daí se clarifica a não coincidência desses dois fenômenos: a suppressio é tão-só a razão e a forma pela qual o exercício de um direito foi limitado (integralmente, neste caso) pela boa-fé objetiva; o posterior exercício - abusivo - desse direito, neste caso, é possível, mas jamais necessário; o abuso de direito, caso então venha, nada obstante, a ocorrer, pressupõe, tanto ontológica quanto cronologicamente, a precedente verificação da suppressio.

Em segundo lugar, da primeira proposição, aceita-se, e definitivamente, que a suppressio e o abuso de direito não coincidem - e, portanto, este não é gênero do qual aquela é espécie (como equivocadamente defende a doutrina tradicional). ${ }^{109}$

Essa não-coincidência acentua-se ainda mais, na medida em que se considera o papel da culpa na estruturação doutrinária de cada figura. $\mathrm{Na}$ Verwirkung, ela ausenta-se totalmente. Já no abuso de direito, ela está presente, seja enquanto mera culpa do exer-

109 Cf. CORDEIRO. Da Boa-Fé... p. 797 e NORONHA. O Direito dos Contratos... p. 186. 
cente que ultrapassa certos limites inerentes ao próprio direito subjetivo e às suas contextualizações social e moral - concepção social e teleológica - seja enquanto dolo, daquele que o exerce, desprovido de interesse próprio legítimo ou utilidade justificante, no propósito de prejudicar a outrem, ou ainda com demasiada indiferença em relação aos interesses deste ${ }^{110}$ - concepção subjetivista e individual."'I

Nega-se - ainda em relação à primeira proposição - todavia, que após verificada a suppressio, em razão desta, possa haver abuso de direito.

Se o objetivo da Verwirkung é suprir, em prol da justiça material, eventual insuficiência ou impossibilidade de prever legalmente limites decadenciais ao exercício de direitos, ${ }^{112}$ a natureza de seus efeitos deve ser equiparada à dos efeitos da decadência. Os desta conduzem à extinção do direito. ${ }^{113}$ Daí se supõe que a suppressio também deva extinguir direitos, e não apenas limitar o seu exercício. Assim, caso incida a Verwirkung e extinga-se o direito, qualquer tentativa superveniente de atuá-lo constituir-se-ia, pela inexistência do direito, em um ato que apenas fingiria ser exercício ou que se situaria além do exercício: ato, portanto, ilícito, em sua acepção originária (distinta da de abu- so de direito - exercício irregular), ou ineficaz. ${ }^{114}$

Conclui-se, em primeiro lugar, desse modo, que a suppressio e o abuso de direito não são apenas dois fenômenos não coincidentes como também unilateralmente excludentes, isto é, se há suppressio não pode haver abuso do direito in suppressio.

Isso posto, qual seria então o fim da Verwirkung especificamente em relação ao abuso de direito? Se a Verwirkung extingue o direito em favor da tranqüilidade social, não pretende ela senão evitar que um direito há muito não efetivado volte a sê-lo e, assim, seja-o abusivamente.

Conclui-se, em segundo lugar, que, quanto à presente questão, a função da suppressio é prevenir o abuso de direito.

\section{CONCLUSÃO}

Seguem-se as conclusões relativas ao que se propôs examinar especificamente em cada capítulo.

A suppressio processa-se consoante o tridimensionalismo jurídico e consiste em um fato que, quando "colorido" pelo valor segurança, ascende à condição de norma, pela ação jurisprudencial.

As relações jurídicas não são indiferentes ao tempo, já que o Direito - cria-

110 RIPERT. A Regra Moral... p.189.

111 NORONHA, op. cit. p. 169-170.

112 CORDEIRO, op. cit.. 815.

113 Veja Orlando Gomes (GOMES. Introdução... p. 495-496 e 505). Analogicamente, também são extintivos, para todos os efeitos, do direito a que se opõem, a cláusula resolutiva e $o$ termo final (cf. arts. 128 e 135, CC/2002). 
do pelo homem, conforme à natureza humana - delimita-as mediante a decadência. Esta, contudo, marcadamente rígida e geral - pois atualmente depende de dispositivo legal - não satisfaz os anseios por justiça material. Subsidiariamente, colmatando as incompletudes que àquela escapam, recorre-se à suppressio, para que esta, flexível e compassiva ao caso concreto, revele o justo onde quer que for chamada.

O princípio da boa-fé, reclamando espaço à moral no racionalismo jurídico, cerca o exercício dos direitos. Exige-lhes a constância e a linearidade minimamente necessárias para que a instabilidade comportamental de cada pessoa não contamine a confiança na ambiência social e desfavoreça ao desenvolvimento regular dos negócios. Desse modo, a boa-fé é a razão, a causa e o instrumento pelos quais a suppressio se realiza.

Por esse mesmo motivo - que atribui papel essencial à boa-fé objetiva na "fisiologia" da perda por protraimento - é mais afeito à razão que se trate a Verwirkung da perspectiva inversa: da daquele que dela se beneficia e cuja confiança tutela-se pela boa-fé. Aderese assim à proposta de Canaris e Menezes Cordeiro; aplaude-se a surrectio.

Em virtude da coerência explicativa e flexibilidade aplicativa, a suppressio é melhor operada (e atinge mais propriamente seu fim) se o for segundo as regras da sistemática móvel: para que se verifique, suas três condições não necessariamente se devem cumular.

Se analisada com rigor, a Verwirkung não consiste em uma forma de abuso de direito. Bem pelo contrário, consi- derada a relação que as vinculam, conclui-se que a sua finalidade não pode ser outra que a prevenção do exercício abusivo dos direitos.

Por último, nada obstante a pergunta inicial desta pesquisa ter sido tão-só a fagulha que a desencadeou e a manteve de pé entre as dificuldades, merece ela evidentemente satisfação: a suppressio não pode pertencer à categoria do abuso de direito, porque ambos os fenômenos não coincidem temporalmente e, indo além, a incidência daquela exclui a deste.

\section{REFERÊNCIAS}

ALVES, J. C. M. Direito Romano. 4. ed. rev. e acrescentada. Rio de Janeiro: Forense, 1979.

AMORIM FILHO, A. Critério Científico para Distinguir a Prescrição da Decadência e para Identificar as Ações Imprescritíveis. Revista dos Tribunais, São Paulo, v. 86, n. 744, p. 725-750, out. 1997.

AZEVEDO, A. J. de. Negócio Jurídico: existência, validade e eficácia. 3. ed. rev. São Paulo: Saraiva, 2000.

BRASIL. Constituição Federal, Código Civil, Código de Processo Civil. Organização dos textos, notas remissivas e índices por Yussef Said Cahali. 3. ed. rev., atual. e ampl. São Paulo: Revista dos Tribunais, 2001.

BRASIL. Novo Código Civil Brasileiro: estudo comparativo com o código civil de 1916. Coordenação de Giselle de Melo Braga Tapai. São Paulo: Revista dos Tribunais, 2002. $600 \mathrm{p}$.

BRASIL. Supremo Tribunal Federal. Súmula n."166. É inadmissível o arrependimento no compromisso de compra e venda sujeito ao regime do DEL 58, de 10.12.1937. Disponível 
em: < http://www.stf.gov.br/jurisprudencia/jurisp.asp >. Acesso em: 14 abr. 2002.

CARLETTI, A. Dicionário de Latim Forense. 8 . ed. totalmente rev. e ampl. São Paulo: Universitária de Direito, 2000. $730 \mathrm{p}$.

CORDEIRO, A. M. da R. e M. Da BoaFé no Direito Civil. Coimbra: Almedina, 1997. 1406 p., p. 797-836.

DINIZ, M. H. Dicionário Jurídico. São Paulo: Saraiva, 1998. 4 v.

GOMES, O. Introdução ao Direito Civil. 18. ed. Rio de Janeiro: Forense, 2001.

ITÁLIA. Codice Civile, Constituzione della Republica Italiana. Organização Enzo Maria Tripodi. 6. ed. Roma: Buffetti, 2000.

KELSEN, H. Teoria Pura do Direito: introdução à problemática científica do direito. São Paulo: Revista dos Tribunais, 2001.

LARENZ, K. Derecho Civil: parte general. Madrid: Rev. de Derecho Privado, 1978. 872 p., p. 302-303.

- Metodologia da Ciência do Direito. 3. ed. Lisboa: Calouste, 1997.

LEAL, A. L. da C. Da Prescrição e da Decadência: teoria geral do direito civil. 2. ed. Rio de Janeiro: Forense, 1959.

LIMA, R. C. Preparação à Dogmática Jurídica. 2. ed. Porto Alegre: Sulina, 1958.

MARQUES, C. L. Contratos no Código de Defesa do Consumidor: o novo regime das relações contratuais. 3. ed. São Paulo: Revista dos Tribunais, 1992.
MARTINS-COSTA, J. A Boa-Fé no Direito Privado: sistema e tópica no processo obrigacional. São Paulo: Revista dos Tribunais, 1999.

MIRANDA, F. C. P. de. Fontes e Evolução do Direito Civil Brasileiro. 2. ed. Rio de Janeiro: Forense, 1981.

Systema de Sciencia Positiva do Direito. Rio de Janeiro: Jacintho Ribeiro dos Santos, 1922.

Tratado de Direito Privado. 3. ed. Rio de Janeiro: Borsoi, 1971.

NORONHA, F. O Direito dos Contratos e seus Princípios Fundamentais: autonomia privada, boa-fé, justiça contratual. São Paulo: Saraiva, 1994.

RÁO, V. O Direito e a Vida dos Direitos. São Paulo: Max Limonad, 1960. v. 1.

REALE, M. Lições Preliminares de Direito. 25. ed. São Paulo: Saraiva, 2000.

Teoria Tridimensional do Direito. 5. ed. rev. e aum. São Paulo: Saraiva, 1994.

RIPERT, G. A Regra Moral nas Obrigações Civis. São Paulo: Saraiva, 1937.

ROUBIER, P. Théorie Générale du Droit: histoire des doctrines juridiques et philosophie des valeurs sociales. 2. ed. rev. e aum. Paris: Sirey, 1951.

SANSEVERINO, P. de T. V. Estrutura Clássica e Moderna da Obrigação. In: MEDEIROS, A. P. C. (Org.). Faculdade de Direito da PUCRS: o ensino jurídico no limiar do novo século. Porto Alegre: EDIPUCRS, 1997. p. 285311.

WIEACKER, F. História do Direito Privado Moderno. 2. ed. Lisboa: Calouste, 1993. 